\title{
POROSIDADE E RETENÇÃO DE ÁGUA EM UM ARGISSOLO SOB MANEJOS CONVENCIONAL E DIRETO SUBMETIDO A COMPRESSÕES UNIDIMENSIONAIS ${ }^{(1)}$
}

\author{
Edson Campanhola Bortoluzzi(2), Vanderlei Rodrigues da Silva ${ }^{(3)}$, \\ Claudia Petry ${ }^{(2)} \&$ Dileta Cecchetti ${ }^{(2)}$
}

\begin{abstract}
RESUMO
A dinâmica da ocupação do espaço poroso pela água e ar em solos sujeitos ao estresse mecânico ainda é pouco conhecida, principalmente quando as pressões situam-se sobre a reta de pré-consolidação. Assim, este trabalho foi realizado com o intuito de quantificar as mudanças no espaço poroso de um Argissolo sob dois sistemas de preparo, submetido a compressões unidimensionais, dando-se ênfase à densidade do solo e ao conteúdo de água retida em dois potenciais. Foram coletadas amostras sob os sistemas plantio convencional (SPC) e plantio direto (SPD), em triplicata e com estrutura preservada, do horizonte superficial Ap (0$0,075 \mathrm{~m}$ ) de um Argissolo Vermelho-Amarelo distrófico abrúptico, do campus da Universidade Federal de Santa Maria, Rio Grande do Sul. Uniformizou-se o conteúdo de água das amostras a $-32 \mathrm{kPa}$ sobre placa porosa em membrana de Richards (panela de pressão), sendo submetidas, em célula odométrica com dreno aberto, às pressões uniaxiais finais de zero, 50, 100 e $200 \mathrm{kPa}$. Após o ensaio, torrões foram separados com as mãos por tração e submetidos, em quadruplicata, a dois potenciais de água (-1.600 e -100 kPa), utilizando-se membrana de Richards (célula). $\mathrm{O}$ volume das amostras e o teor de água gravimétrica foram determinados por pesagens sob empuxo e após secagem em estufa a $105^{\circ} \mathrm{C}$. Aplicou-se a análise de variância nos resultados, e uma análise de regressão foi aplicada quando necessária. A densidade do solo respondeu linearmente para o SPD e de forma quadrática para o SPD com o aumento das pressões. O conteúdo de água variou de forma quadrática com o aumento das pressões aplicadas em ambos os sistemas de preparo do solo. Explica-se $85 \%$ da retenção de água do solo pela variação da pressão unidimensional aplicada, sendo a resposta positiva para o SPC e negativa para o SPD. As mudanças na densidade do solo e no conteúdo de água gravimétrica foram importantes em ambos os sistemas de preparo no potencial de água de -100 kPa. Pode-se inferir que o solo sob sistema de preparo convencional foi mais
\end{abstract}

\footnotetext{
(1) Recebido para publicação em novembro de 2007 e aprovado em junho de 2008 .

${ }^{(2)}$ Universidade de Passo Fundo, Faculdade de Agronomia e Medicina Veterinária - UPF/FAMV. Campus I, Caixa Postal 611, CEP 99001-970 Passo Fundo (RS). E-mail: edsonb@upf.br

(3) Universidade Federal de Santa Maria - UFSM. Centro de Educação Superior do Norte, RS CESNORS, CEP 98400-000 Frederico Westphalen (RS). E-mail: vanderlei@smail.ufsm.br
} 
sensível ao estresse mecânico que aquele sob plantio direto, evidenciando a diminuição da porosidade e consequentemente da proporção de ar.

Termos de indexação: afinidade entre solo-água, potencial de água, sistema conservacionista, porosimetria a mercúrio.

\section{SUMMARY: POROSITY AND WATER RETENTION IN ANACRISOL UNDER CONVENTIONAL AND NO-TILL SYSTEMS UNDER UNIAXIAL COMPRESSION}

To date, little is known about the dynamics of water and air in porous spaces of soils exposed to mechanical stresses, mainly when the pressure is located on the pre-consolidation line. This study aimed to quantify the changes in the porous spaces of an Acrisol under two tillage systems, submitted to increasing one-dimensional compression, emphasizing the bulk density and water retention at two water potential levels. Undisturbed soil samples were collected under conventional tillage $(C T)$ and no-till (NT), with three replications, from the Ap surface horizon $(0-0.075 \mathrm{~m})$ of an Red-Yellow Dystrophic Acrisol at the Universidade Federal de Santa Maria in Rio Grande do Sul State. The sample water content was standardized at $-32 \mathrm{kPa}$ in a Richards membrane-plate extractor and the samples were submitted to one-dimensional pressures of $0,50,100$, and $200 \mathrm{kPa}$ in an open-drained oedometric cell. After the trial, clods were pushed by hand and were submitted in four replications to two water potential levels (-1.600 and $-100 \mathrm{kPa}$ ) in a Richards membrane (cell). Sample volumes as well as gravimetric water contents were determined by weighing in kerosene after oven-drying at $105^{\circ} \mathrm{C}$. ANOVA was performed as well as regression analysis, whenever necessary. The response of soil bulk density to the increasing pressure was a linear function for SPD and a square function for SPD. In both management systems the water content was exponentially related with the stress levels. Variation in water retention can be explained by $85 \%$ by the one-dimensional compression, which was positive for CT and negative for NT. At a water potential of -100 kPa the changes in bulk density and gravimetric water content were relevant in both management systems. It was concluded thatthe soil under $C T$ is more sensitive to mechanical stress than that under $N T$, as demonstrated in the magnitude of reduction of porous space and air proportion contained within.

Index terms: soil-water relation, water potential, sustainable system, mercury porosimetry.

\section{INTRODUÇÃO}

O uso e manejo inadequados do solo podem ter, sob vários aspectos, conseqüências negativas para as propriedades físicas dos solos e para as culturas. Entre elas, cita-se a compactação do solo, que compromete a qualidade geral dos solos, principalmente sob sistema de plantio direto, com reflexos na produtividade das culturas (Merotto Júnior \& Mundstock, 1999; Beutler et al., 2005) e mesmo na sustentabilidade das propriedades rurais em longo prazo (Andreoli \& Tellarini, 2000). A manifestação mais comum da compactação do solo é observada pelo aumento na densidade e na resistência do solo à penetração das raízes das plantas e, como conseqüência, observa-se a diminuição da porosidade e da circulação de água no solo (Dias Junior, 2000; Boizard et al., 2002).

Em solos agrícolas, a causa preponderante da compactação do solo é o tráfego de máquinas, equipamentos e animais, logo é a aplicação de cargas que resulta em estresse mecânico do solo. Essa situação é agravada quando o solo encontra-se com umidade elevada ou quando o estresse ultrapassa os níveis até então suportados (Kondo \& Dias Junior, 1999; Dias Junior, 2000). Em sistema de preparo convencional, a camada superficial é revolvida seguidamente por arações e gradagens, o que incrementa a porosidade do solo nessa camada, apesar da pequena capacidade de ser mantida indefinidamente após o revolvimento. No entanto, na camada subjacente de solo, limitada ao alcance dos implementos, a compactação é severa e se faz perceber principalmente em longo prazo e em culturas perenes (Alcântara \& Ferreira, 2000; Boizard et al., 2002). No entanto, a compactação superficial nesse sistema é remediada pela interferência do implemento de preparo a cada estação de plantio. Em contrapartida, em sistemas conservacionistas, cuja ausência de revolvimento do solo é uma premissa, o histórico de estresse mecânico sofrido pelo solo é mais longo. Assim, os efeitos 
negativos da compactação podem ser paulatinamente agravados até o ponto de inviabilizar a continuidade do sistema (Hill, 1990; Albuquerque et al., 2001; Stone \& Silveira, 2001).

Em resumo, o solo é organizado a partir da sua fase sólida, cujas propriedades físicas variam de acordo com a constituição mineralógica (Bruand \& Tessier, 2000) e com a forma e distribuição do tamanho de partículas (Panayiotopoulos \& Mullins, 1985; Bastet et al., 1998; Bruand et al., 2005). As fases líquida e gasosa são dependentes dessa organização, coexistindo com a fase sólida, porém em proporções diversas. A retenção de água no solo pode ser alterada com a modificação do espaço poroso, fenômeno que interfere diretamente na disponibilidade de água e na eficiência do uso da água pelas culturas (Canali \& Roloff, 1997; Dias Junior, 2000). Nesse sentido, modificações na estrutura e porosidade do solo podem ser decorrentes da aplicação de pressões sobre o solo. Horn \& Rostek (2000), estudando um solo que sofreu uma compressão unidimensional de 150 kPa, observaram a diminuição da permeabilidade ao ar e da porosidade do solo, sendo em maior magnitude no solo sob plantio convencional que aquele manejado em plantio direto.

Em contrapartida, a capacidade do solo de resistir a estresses mecânicos garante a qualidade da porosidade e a relação entre as fases líquida e gasosa. Em testes de compressão unidimensional, esse limite é conhecido como ponto de pré-consolidação, a partir do qual (curva de compressão virgem) a qualidade da porosidade, seu volume e funcionalidade em relação à água são intensamente alterados (Horn \& Lebert, 1994; Dias Junior, 2000; Richards et al., 2000; Trautner et al., 2003).

Diversos trabalhos têm sido realizados com o intuito de identificar e compreender o solo em condições próximas ao ponto de pré-consolidação, a fim de evitar situações que o ultrapassem. Nesse sentido, destacamse propriedades como a umidade crítica (Kondo \& Dias Júnior, 1999; Dias Junior, 2000; Silva et al., 2002a), a textura do solo (Larson et al., 1980; Silva et al., 2002a) e a presença de resíduos vegetais em superfície como fator de resistência ao estresse mecânico (Stone \& Ekwue, 1993; Braida et al., 2006). A matéria orgânica e a argila, por exemplo, atuam como pontes de transferência de energia entre as partículas, aumentando a resistência da estrutura à fricção e, por conseqüência, ao colapso (Panayiotopoulos \& Mullins, 1985). Segundo estudo de Bruand et al. (2005), a variação, mesmo que pequena, nos teores desses constituintes pode afetar consideravelmente as propriedades físico-mecânicas do solo. Segundo Panayiotopoulos \& Mullins (1985), a máxima diminuição de vazios numa amostra de areia é obtida na condição de ausência de água, mas também quando próxima da saturação. Em um Argissolo de textura arenosa, estudado por Silva et al. (2002b), a máxima compressão foi obtida com cerca de $30 \%$ de água no solo, valor muito inferior ao obtido em um Latossolo, que se mostrou mais resistente ao estresse com a mesma proporção de água. Esses estudos serviram como base para o dimensionamento de máquinas e a adequação de práticas agrícolas em momentos de menor suscetibilidade dos solos à compressão.

Em geral, solos arenosos retêm pouca água quando há baixo potencial de água, diminuindo intensamente o conteúdo com o aumento do potencial. Nesse sentido, o comportamento mecânico-hídrico desses solos assemelha-se aos de amostras constituídas principalmente de partículas da fração areia, onde estas se organizam formando um arco com uma estrutura de conjunto muito resistente às pressões, se comparada com materiais mais finos (Duran et al., 1998; Delage \& Fry, 2000). Contudo, ao ultrapassar o ponto de pré-consolidação, a estrutura é colapsada e as partículas maiores ocupam a porosidade pretérita, podendo alterar substancialmente os tamanhos de poros do solo e a retenção de água a um dado potencial de água (Duran et al., 1998).

Nesse sentido, este trabalho foi realizado com o intuito de quantificar as mudanças no espaço poroso de um Argissolo sob dois sistemas de preparo submetido a compressões unidimensionais, dando-se ênfase à densidade do solo e no conteúdo de água retida em dois potenciais.

\section{MATERIAL E MÉTODOS}

\section{Localização do experimento e caracterização do solo}

As amostras de solo utilizadas no trabalho originaram-se da área experimental da Universidade Federal de Santa Maria, Santa Maria, Rio Grande do Sul-RS. A região é continental pertencente à Depressão Central do Estado, sendo regida por um clima subtropical úmido do tipo Cfa, segundo a classificação de Koëppen. A precipitação pluviométrica atinge em média $1.700 \mathrm{~mm}$ anuais, sendo bem distribuída ao longo do ano, e a temperatura média anual é de $19,2^{\circ} \mathrm{C}$. O relevo da região é suave ondulado, com predomínio de coxilhas.

O solo é classificado como Argissolo VermelhoAmarelo distrófico abrúptico (Embrapa, 2006) e estava sendo cultivado com culturas anuais (aveia/soja/ ervilhaca/milho) sob preparo convencional (SPC) plantio direto (SPD). Esses sistemas foram implantados sobre um campo nativo, porém, no momento da amostragem, em 2002, apresentaram um histórico de seis e 30 anos, respectivamente.

Amostras de solos foram coletadas nos horizontes do perfil, secas ao ar e peneiradas em malha de $2 \mathrm{~mm}$, constituindo, assim, a fração de terra fina seca ao ar (TFSA). Foram caracterizadas quimicamente, segundo Tedesco et al. (1995), no Laboratório de Solos da Universidade Federal de Santa Maria. A 
capacidade de troca de cátions efetiva $\left(\mathrm{CTC}_{\mathrm{E}}\right)$ foi calculada pela soma dos cátions $\left(\mathrm{Ca}^{2+}, \mathrm{Mg}^{2+} \mathrm{e} \mathrm{K}^{+}\right)$mais $\mathrm{Al}^{3+}$; e à CTC potencial $\left(\mathrm{CTC}_{7}\right)$ somaram-se os cátions mais $\mathrm{H}+\mathrm{Al}$ estimados pelo $\mathrm{pH}$ SMP. O carbono orgânico total (COT) foi determinado utilizando-se um auto-analisador elementar de C, $\mathrm{HeN}$. A granulometria do solo foi determinada em suas três frações por tamisagem (fração areia) e por sedimentação (frações silte e argila) (Quadro 1).

\section{Ensaios de compressão unidimensional}

Amostras não deformadas de solo da camada superficial de 0-0,075 $\mathrm{m}$ foram coletadas em triplicata, em 2002, com auxílio de um trado de ferro de $0,1 \mathrm{~m}$ de diâmetro e encaminhadas ao Laboratório de Solos do INRA de Versailles - França. Para os ensaios de compressão unidimensional, extraíram-se dessas amostras de solo três subamostras com auxílio de anéis de $\mathrm{Cu}$ de 0,022 $\mathrm{m}$ de altura por 0,05 $\mathrm{m}$ de diâmetro. Esses anéis, contendo solo com estrutura preservada, representando a profundidade de $0-0,075 \mathrm{~m}$, umidade e variabilidade natural do campo, foram submetidos à saturação da porosidade com água. O procedimento constou da colocação das subamostras dentro de um dessecador, e, sob vácuo, foram submetidas à saturação com água por ascensão capilar. Depois, os anéis foram submetidos a uma tensão de água de $-32 \mathrm{kPa}$ em célula de Richards (Richards, 1941), que, segundo Silva et al. (2002a), corresponde ao potencial de água, para este solo, que proporciona maior sensibilidade à compactação.

Os ensaios de consolidação uniaxial foram realizados sobre os anéis contendo amostras de solo com estrutura preservada do campo com conteúdo de água controlado. Utilizou-se, para isso, uma célula odométrica - dispositivo composto por um êmbolo que injeta um líquido incompressível para o interior da célula odométrica (Delage \& Cui, 2001). Por meio do programa de computador Hydrocon ${ }^{\circledR}$, que gerencia a célula, programaram-se ensaios de consolidação uniaxial com a aplicação de pressões unidimensionais de zero, 50, 100 e $200 \mathrm{kPa}$, alcançadas aplicando-se pressões crescentes de $5 \mathrm{kPa}$ em estádios de cinco minutos cada. Essa configuração permitiu que houvesse tempo para a completa transferência da pressão aplicada pelo êmbolo à amostra de solo. Vale ressaltar que os ensaios ocorreram em dreno aberto, isto é, o conteúdo de água da amostra pode ser drenado como resultante da aplicação das pressões unidimensionais.

\section{Estudo do conteúdo de água em diferentes potenciais de água no solo}

Ao final dos ensaios, dispunham-se de 24 anéis oriundos de solos da profundidade de $0-0,075 \mathrm{~m}$ de dois sistemas de preparo SPC e SPD e submetidos a quatro pressões unidimensionais em três repetições. As amostras de solo correspondente a esses cilindros foram quebradas, com auxílio da tração dos dedos, em torrões de volume aproximado entre 3 e $5 \mathrm{~cm}^{3}$. Os torrões, referentes a cada sítio e a cada pressão aplicada, foram misturados, e quatro deles submetidos a um potencial de água no solo de $-1.600 \mathrm{kPa}$ e quatro de $-100 \mathrm{kPa}$. Utilizaram-se, para isso, células de Richards, onde as amostras permaneceram confinadas por uma semana. Após esse período, os torrões foram submetidos à determinação do conteúdo de água e da densidade do solo, por pesagens nos potenciais de água equivalentes a - 1.600 e $-100 \mathrm{kPa}$.

A densidade dos torrões foi determinada pelo método do empuxo de Arquimedes (Monnier et al., 1973). Nesse método, os torrões foram mergulhados completamente em querosene, onde a massa sob

Quadro 1. Características do perfil de solo de um Argissolo Vermelho-Amarelo distrófico abrúptico de Santa Maria, RS

\begin{tabular}{|c|c|c|c|c|c|c|c|c|c|c|}
\hline \multirow{2}{*}{ Preparo } & \multirow{2}{*}{$\mathrm{Hz}$} & \multicolumn{3}{|c|}{ Granulometria $(\mu \mathrm{m})$} & \multirow{2}{*}{ Profundidade } & \multirow{2}{*}{$\operatorname{COT}^{(1)}$} & \multirow{2}{*}{$\mathbf{p H ~} \mathrm{H}_{2} \mathrm{O}$} & \multirow{2}{*}{ Cor } & \multirow{2}{*}{$\mathrm{CTC}_{\mathrm{E}}$} & \multirow{2}{*}{$\mathrm{CTC}_{7}$} \\
\hline & & $<2$ & $2-50$ & $50-2000$ & & & & & & \\
\hline & & & $\%$ & 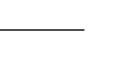 & $\mathrm{m}$ & $\%$ & & & $-\mathrm{mm}$ & $\mathrm{zg}^{-1}-$ \\
\hline \multirow[t]{5}{*}{$\mathrm{SPC}$} & Ap1 & 11,0 & 24,3 & 64,7 & $0-0,075$ & $0,77(0,03)$ & $5,3(0,27)$ & 10YR $3 / 3$ & $38,0(4,0)$ & $41,7(0,6)$ \\
\hline & Ap 2 & 11,0 & 24,3 & 64,7 & $0,075-0,15$ & $0,70(0,04)$ & $5,8(0,17)$ & $10 Y R 3 / 3$ & $39,3(5,8)$ & $40,0(1,0)$ \\
\hline & $\mathrm{A} 2$ & 13,6 & 26,3 & 60,1 & $0,15-0,30$ & $0,59(0,04)$ & $5,4(0,04)$ & 10YR 3/2.5 & $39,0(2,0)$ & $38,3(5,8)$ \\
\hline & $\mathrm{E}$ & 9,5 & 30,7 & 59,8 & $0,30-0,65$ & $0,37(0,01)$ & $4,8(0,25)$ & 10YR 4/4 & $24,7(0,6)$ & $29,3(2,3)$ \\
\hline & $\mathrm{Bt}$ & 39,7 & 19,2 & 41,1 & $0,65+$ & $0,49(0,07)$ & $4,5(0,06)$ & $5 \mathrm{YR} 4 / 4$ & $69,7(6,7)$ & $84,7(5,0)$ \\
\hline \multirow[t]{5}{*}{ SPD } & Ap1 & 11,9 & 24,7 & 63,4 & $0-0,075$ & $1,04(0,17)$ & $4,9(0,16)$ & $10 Y R 3 / 3$ & $38,3(7,5)$ & $47,7(7,2)$ \\
\hline & Ap2 & 11,9 & 24,7 & 63,4 & $0,075-0,15$ & $0,78(0,09)$ & $4,4(0,12)$ & 10YR $3 / 3$ & $30,3(2,3)$ & $45,3(1,2)$ \\
\hline & $\mathrm{A} 2$ & 13,6 & 26,2 & 60,2 & $0,15-0,30$ & $0,71(0,02)$ & $4,4(0,14)$ & $7.5 Y R 3 / 2$ & $32,7(1,5)$ & $42,3(4,2)$ \\
\hline & $\mathrm{E}$ & 16,1 & 24,6 & 59,3 & $0,30-0,50$ & $0,46(0,01)$ & $4,3(0,03)$ & $10 \mathrm{YR} 4 / 3$ & $25,3(1,5)$ & $36,7(2,1)$ \\
\hline & $\mathrm{Bt}$ & 46,9 & 18,4 & 34,7 & $0,50+$ & $0,53(0,03)$ & $4,0(0,08)$ & 5YR 4/6 & $72,3(4,5)$ & $93,3(0,6)$ \\
\hline
\end{tabular}

(1) Carbono orgânico total. Os valores entre parênteses são os desvios-padrão de três repetições em relação à média. 
empuxo foi determinada. A razão entre a massa da amostra sob empuxo e a densidade do querosene permitiu a estimativa do volume da amostra. Os torrões foram então pesados após secagem em estufa a $105{ }^{\circ} \mathrm{C}$. A razão entre a massa dos torrões secos e seu respectivo volume constituiu-se na densidade $(\sigma)$ da amostra. O conteúdo de água gravimétrica foi calculado, bem como o volume de vazios, de ar e de água. Por fim, os índices de vazios, de água e de ar foram calculados por meio da razão entre o volume dessas propriedades e o volume de sólido das amostras após terem sido submetidas a diferentes compressões unidimensionais.

Torrões de solo coletados nas profundidades de 0-0,075 $\mathrm{m}$ e 0,075-0,15 $\mathrm{m}$, com volume entre 2 e $3 \mathrm{~cm}^{3}$, foram mantidos durante $24 \mathrm{~h}$ em estufa a $90^{\circ} \mathrm{C}$ a fim de padronizar sua umidade para serem submetidos à intrusão de Hg. Para isso, utilizaram-se porosímetros a Hg modelos Pascal 140 e 440, que proporcionam pressões de intrusão desde $0,1 \mathrm{kPa}$ a $400.000 \mathrm{kPa}$, sendo controlados pelo programa de computador Pascal 140/240/440. Essas pressões permitem a intrusão de $\mathrm{Hg}$ em poros de tamanho que variam de 58.000 até $31,8 \mathrm{~nm}$ de diâmetro. A relação entre a pressão e o volume de $\mathrm{Hg}$ que penetra nos poros da amostra são fatores que compõem o espectro do espaço poroso do solo. O fenômeno descrito por Washburn (1921) pode também ser representado pela equação:

$$
\mathrm{Pr}=-2 \pi \mathrm{r} \gamma \cos \alpha
$$

sendo $\mathrm{P}=$ pressão absoluta aplicada $\left(\mathrm{kg} \mathrm{cm}^{-2}\right) ; \mathrm{r}=$ raio do poro $(\mathrm{nm}) ; \gamma=$ tensão superficial, $480 \mathrm{nN} \mathrm{m}^{-1}$; e $\alpha=$ ângulo de contato, $141,30^{\circ}$.

Ao simplificar a equação, tem-se:

$$
\mathrm{r}=7.500 / \mathrm{P}
$$

A descrição do método pode ser obtida em detalhe no trabalho de Bruand (1985).

A análise estatística foi realizada sobre os resultados de retenção de água, densidade do solo e os índices de vazios, ar e água. Realizou-se uma análise da variância (ANOVA) utilizando um esquema inteiramente casualizado com parcelas subdivididas. A parcela principal refere-se aos manejos SPC e SPD, e a subsubparcela aos níveis de compressão unidimensional aplicados e aos potenciais ( $\Psi)$ de água no solo de $-1.600 \mathrm{kPa}$ e $-100 \mathrm{kPa}$. Quando significativo na Anova para os níveis de compressão, aplicaram-se regressões. Correlações de Pearson também foram realizadas entre os dados. A caracterização da porosidade ou distribuição de tamanho de poros, anterior à aplicação do estresse, foi apresentada na forma de espectros de intrusão de $\mathrm{Hg}$ construídos por meio da derivada primeira do volume de $\mathrm{Hg}$ que penetrou na amostra pelo logaritmo do raio do poro $(\gamma \mathrm{V} / \gamma \log \mathrm{r})$.

\section{RESULTADOS E DISCUSSÃO}

Visualiza-se na figura 1 os espectros da porosidade do solo anterior à aplicação do estresse mecânico. Nessa figura, a abscissa é representada pelo diâmetro de poros em escala logarítmica e na ordenada à derivada do volume de $\mathrm{Hg}$ acumulado pelo raio do poro. A porosidade do solo pode ser representada, nos diagramas, pelos três picos, correspondendo ao diâmetro modal de poros. O primeiro representa poros de diâmetro inferior a $0,1 \mu \mathrm{m}$, denominado microporos; o segundo, pelo diâmetro entre 0,1 e $6 \mu \mathrm{m}$, denominado mesoporos; e o terceiro àqueles superiores a $6 \mu \mathrm{m}$, considerados macroporos segundo a classificação utilizada por Bruand (1985).

Observa-se, no preparo convencional, profundidade de 0,075 a $0,15 \mathrm{~m}$, que houve praticamente a subtração, pico presente do pico a $30 \mu \mathrm{m}$ na profundidade de $0 \mathrm{a}$ $0,075 \mathrm{~m}$ de ambos os preparos de solo (SPD e SPC). $\mathrm{Na}$ profundidade de $0-0,075 \mathrm{~m}$, para ambos os preparos de solo os espectros foram similares, porém com tendência de diminuir a macroporosidade em detrimento da mesoporosidade. No SPD, para ambas as profundidades, houve um comportamento similar entre si em relação às curvas e os diâmetros modais.

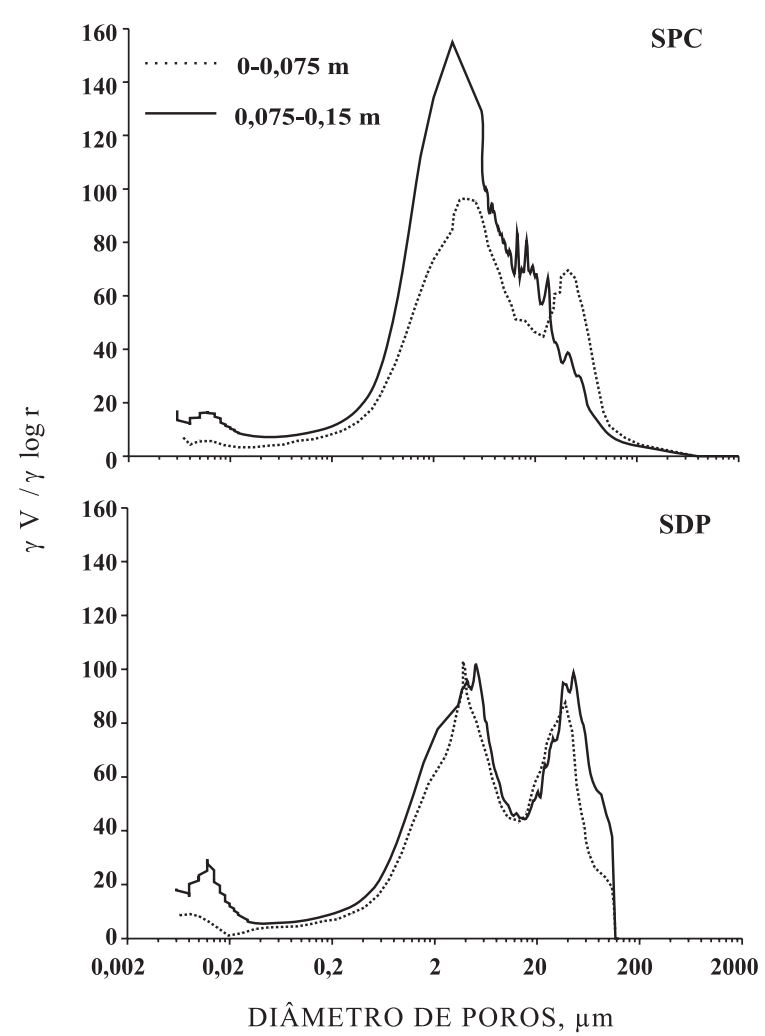

Figura 1. Diagramas representando o diâmetro modal de poros devido à intrusão de $\mathrm{Hg}$ em amostras de um Argissolo Vermelho-Amarelo distrófico abrúptico, profundidades de 00,075 m e 0,075-0,15 m, submetidos a dois preparos de solo (SPD e SPC). 
Diâmetros de poros inferiores a $0,1 \mu \mathrm{m}$ correspondem àquela proporcionada pela fração argila e se mostram insensíveis ao manejo (Figura 1).

Apesar da similaridade nos espectros do espaço poroso dos solos, nos dois sistemas de preparo, principalmente na maior profundidade (Figura 1), a estrutura do solo oriunda de diferentes sistemas de preparo pode apresentar comportamentos distintos quando submetida a níveis de estresse mecânico.

Nesse sentido, no quadro 2, são apresentados os resultados de densidade do solo após a aplicação dos níveis de compressão unidimensional (zero, 50, 100 e $200 \mathrm{kPa}$ ) e o conteúdo de água gravimétrica retido nos potenciais de $-1.600 \mathrm{kPa}$ e $-100 \mathrm{kPa}$. Observa-se que, para a variável densidade do solo, houve significância pelo teste $t$ entre os dois manejos estudados, mas não para os dois potenciais de água aplicados, convergindo com o encontrado na literatura (Hakansson et al., 1988; Unger \& Jones, 1998; Carter et al., 1999; Albuquerque et al., 2001; Secco et al., 2004; Collares et al., 2006). Isso indica que a estrutura do solo é condicionada ao manejo de solo. No preparo convencional, há menor resistência da estrutura com o aumento da densidade do solo resultante do aumento da pressão unidimensional.

Observa-se ainda que a densidade do solo foi maior para o SPC que para o SPD, respondendo de forma linear e quadrática, respectivamente, com o aumento do estresse mecânico (Figura 2). Nesse sentido, o solo sob SPC aumentou sua densidade em $0,3 \mathrm{~g} \mathrm{~cm}^{-3}$ para cada $50 \mathrm{kPa}$ de pressão aplicada $\left(\mathrm{R}^{2}=0,51\right)$. Para o $\mathrm{SPD}$, a resposta foi similar para os primeiros níveis de estresse, porém aumentando intensamente sob $200 \mathrm{kPa}$ de pressão aplicada. Isso demonstra que o comportamento do solo sob SPD e SPC ao estresse é distinto. O solo sob SPC é mais susceptível, aumentando a densidade com o aumento das pressões aplicadas, mesmo naquelas consideradas pequenas (50 e $100 \mathrm{kPa}$ ). Já para o solo sob SPD, a estrutura apresenta-se mais resistente aos pequenos estresses, até a pressão de $100 \mathrm{kPa}$, a partir da qual houve aumento mais intenso da densidade do solo. A maior densidade do solo foi verificada sob SPC, provavelmente devido ao histórico da área de curto prazo sob SPD, com cerca de seis anos, visto que solos sob SPD tendem a aumentar a sua densidade, principalmente nas menores profundidades, com a consolidação do sistema (Carter et al., 1999; Correchel et al., 1999; Reinert et al., 2001; Tavares Filho et al., 2001).

Outro ponto interessante refere-se à manutenção do volume de solo em diferentes potenciais de água a que a amostra é submetida, logo sua densidade mantém-se inalterada com a variação da umidade. Isso é plausível em função do baixo teor de matéria orgânica e de argila dos solos (15\%), mesmo que parte da fração argila apresente argilominerais $2: 1 \mathrm{com}$ entrecamadas expansíveis, como relatado por Bortoluzzi et al. (2005a, 2008). Mesmo havendo a expansão e retração das entrecamadas dos argilominerais 2:1 em função do conteúdo de água, o fenômeno não é o suficiente para ser captado nas variáveis volume e densidade do solo, como acontece nos solos mais argilosos (Lesturgez et al., 2005). Contudo, nos solos arenosos, é provável que o fenômeno de expansão volumétrica dos argilominerais $2: 1$ e da matéria orgânica com o aumento no teor de água não se manifeste macroscopicamente, porque ocorre dentro de meso e macroporos. Por outro lado, solos que não têm a capacidade macroscópica de expansão e retração em volume, em função da umidade, podem apresentar baixa resiliência quanto à compactação, ou seja, apresentar pouca capacidade de diminuir sua densidade devido aos ciclos de umedecimento e

Quadro 2. Densidade do solo e conteúdo de água gravimétrica de um Argissolo Vermelho-Amarelo distrófico abrúptico, profundidade de $\mathbf{0}-0,075 \mathrm{~m}$, submetidos a dois preparos de solo (SPD e SPC), a níveis crescentes de compressão unidimensional e a dois potenciais de água no solo $(-1.600$ e $-100 \mathrm{kPa})$

\begin{tabular}{|c|c|c|c|c|c|}
\hline \multirow{2}{*}{ Manejo } & \multirow{2}{*}{ Potencial de água } & \multicolumn{3}{|c|}{ Pressão unidimensional aplicada, } & \multirow[b]{2}{*}{200} \\
\hline & & Zero & 50 & 100 & \\
\hline & $\mathrm{kPa}$ & \multicolumn{4}{|c|}{ Densidade do solo, $\mathrm{g} \mathrm{cm}^{-3}$} \\
\hline $\mathrm{SPC}^{* *}$ & $\begin{array}{c}-100^{\mathrm{ns}} \\
-1.600\end{array}$ & $1,69^{*} \mathrm{a}$ & $1,69 \mathrm{a}$ & $1,76 \mathrm{a}$ & $1,74 \mathrm{a}$ \\
\hline \multirow[t]{2}{*}{ SPD } & $\begin{array}{l}-100^{\mathrm{ns}} \\
-1.600\end{array}$ & $1,61^{*} \mathrm{~b}$ & $1,61 \mathrm{~b}$ & $1,59 \mathrm{~b}$ & $1,65 \mathrm{~b}$ \\
\hline & & \multicolumn{4}{|c|}{ Água gravimétrica, $\mathrm{g} \mathrm{g}^{-1}$} \\
\hline $\mathrm{SPC}^{* *}$ & $\begin{array}{l}-100^{* *} \\
-1.600\end{array}$ & $\begin{array}{l}0,122^{*} \\
0,054^{\mathrm{ns}}\end{array}$ & $\begin{array}{l}0,121 \\
0,055\end{array}$ & $\begin{array}{l}0,117 \\
0,053\end{array}$ & $\begin{array}{l}0,129 \\
0,052\end{array}$ \\
\hline SPD & $\begin{array}{l}-100^{* *} \\
-1.600\end{array}$ & $\begin{array}{l}0,141^{*} \\
0,061 \mathrm{~ns}\end{array}$ & $\begin{array}{l}0,150 \\
0,062\end{array}$ & $\begin{array}{l}0,166 \\
0,062\end{array}$ & $\begin{array}{l}0,158 \\
0,061\end{array}$ \\
\hline
\end{tabular}

Letras minúsculas comparam, na coluna, as médias entre os sítios, independente do potencial de água no solo, pelo teste de Tukey a $5 \%$. ${ }^{*} \mathrm{p}<0,05 ;{ }^{* *} \mathrm{p}<0,01$; e ns, não significativo. 


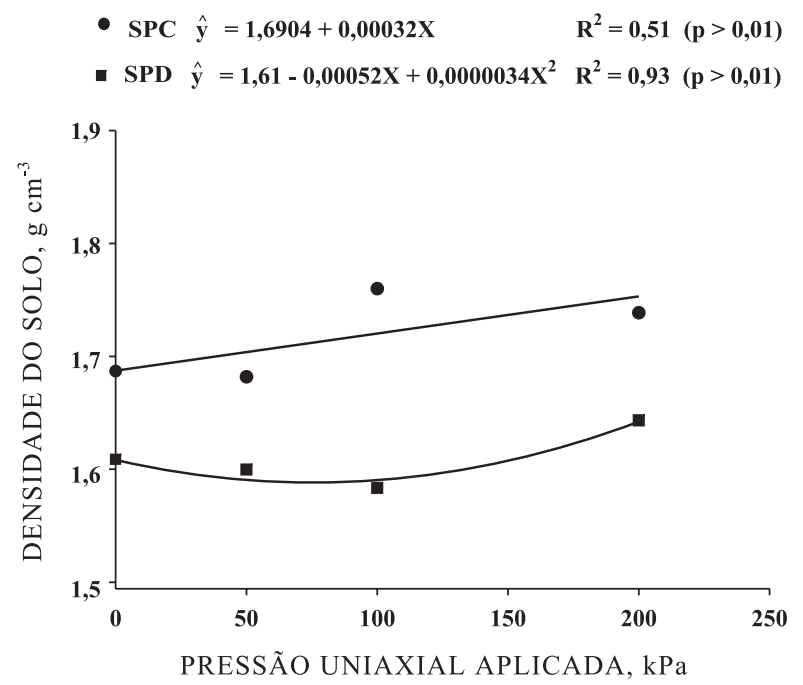

Figura 2. Equações de regressão entre a densidade do solo de um Argissolo Vermelho-Amarelo distrófico abrúptico, profundidade de 0-0,075 m, sob dois sistemas de preparo do solo (SPC e SPD) em funções dos níveis de compressão unidimensional aplicados.

secagem do solo. Nesse sentido, o rompimento da camada compactada dependerá de fatores externos, como a intervenção por meio de implementos especiais ou de plantas com sistema radicular pivotante (Abreu et al., 2004; Genro Junior et al., 2004).

Para o conteúdo de água do solo (Figura 3) houve significância para o preparo do solo e os potenciais de água avaliados. Assim, para o potencial de água de $100 \mathrm{kPa}$, o solo sob SPD apresentou maior conteúdo de água, mesmo na testemunha $(0 \mathrm{kPa})$, porém responde de forma quadrática e positiva com o estresse aplicado. Isso indica que a compactação teve efeito, incrementando o conteúdo de água no solo, nos três primeiros níveis de estresse, reduzindo o tamanho dos macroporos e armazenando mais água, mas tendeu a diminuir no maior nível $(200 \mathrm{kPa})$. Isso pode ser atribuído ao colapso da estrutura próximo à pressão de $200 \mathrm{kPa}$, onde os macroporos foram destruídos e o conteúdo de água drenou da amostra. Silva et al. (2004), estudando solos com teor de argila similar ao deste trabalho, verificaram resposta similar quando da aplicação de pressões menores que $100 \mathrm{kPa}$.

Comportamento inverso foi observado no SPC, ou seja, houve tendência de estabilidade nos três primeiros níveis de estresse mecânico, aumentando o conteúdo de água na pressão de $200 \mathrm{kPa}$. Analisando os valores de densidade do solo (Quadro 2) nesse sistema de preparo, percebe-se que há maior estado de compactação no SPC em relação ao SPD. Possivelmente, somente pressões próximas de $200 \mathrm{kPa}$ provocaram alguma redução nos macroporos do solo e, conseqüentemente, alteração no conteúdo de água nessas amostras (Silva et al., 2002a; Silva et al., 2004).
Para o potencial de água de $-1.600 \mathrm{kPa}$, os estresses mecânicos não foram suficientes para alterar o conteúdo de água gravimétrico do solo (Figura 3). Isso era esperado, visto que, nesse potencial, o conteúdo de água é mais intimamente ligado às cargas elétricas das partículas minerais e orgânicas da fase sólida do que à porosidade (Prost et al., 1998; Bortoluzzi et al., $2005 b)$. No entanto, nesse potencial (-1.600 kPa), o solo sob SPD apresentou tendência de maior conteúdo de água que o do SPC, explicado provavelmente pelo maior teor de matéria orgânica, visto que a composição mineralógica dos sítios e a CTC são similares (Quadro 1). Nesse potencial de água, o caráter hidrófilo/hidrófobo dos sítios das partículas e a capacidade de argilominerais se hidratarem nas entrecamadas gerenciam o conteúdo de água (PernesDebuyser \& Tessier, 2004).

Em uma análise dos índices de vazios do solo (Figura 4a), pode-se observar um comportamento dinâmico entre o espaço poroso ocupado pela água e ar em função dos níveis de estresse uniaxial aplicados.

$\mathrm{O}$ índice de vazios tende a diminuir, principalmente para o solo sob SPC, com o aumento da pressão aplicada, mesmo em menor potencial de água. Isso é concordante com o aumento da densidade do solo em função da pressão aplicada (Figura 2). O índice de água do solo sob SPC (Figura 4b), apresentou comportamento contrário, aumentando com a pressão aplicada no potencial de água $(-100 \mathrm{kPa})$.

Já para o índice de ar, observa-se que, em ambos os sistemas de preparo do solo (Figura 5a) e potenciais de água (Figura 5b), houve diminuição da proporção do espaço poroso ocupado por ar com a aplicação das pressões. Entretanto, esse comportamento não foi significativo para discriminar o efeito dos sistemas

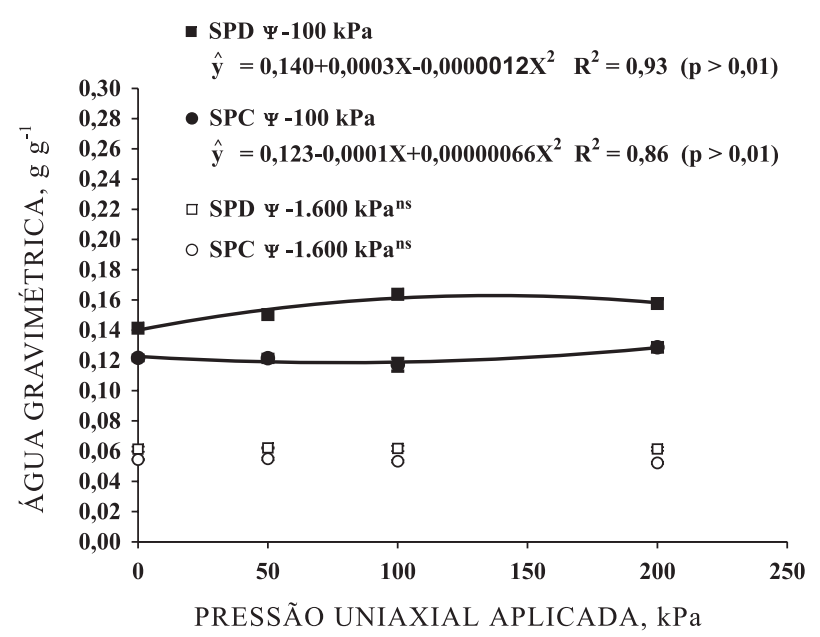

Figura 3 Equações de regressão entre o conteúdo de água gravimétrica de um Argissolo VermelhoAmarelo distrófico abrúptico, profundidade de 0-0,075 m, sob dois sistemas de preparo do solo (SPC e SPD) em funções dos níveis de compressão unidimensional aplicados. 


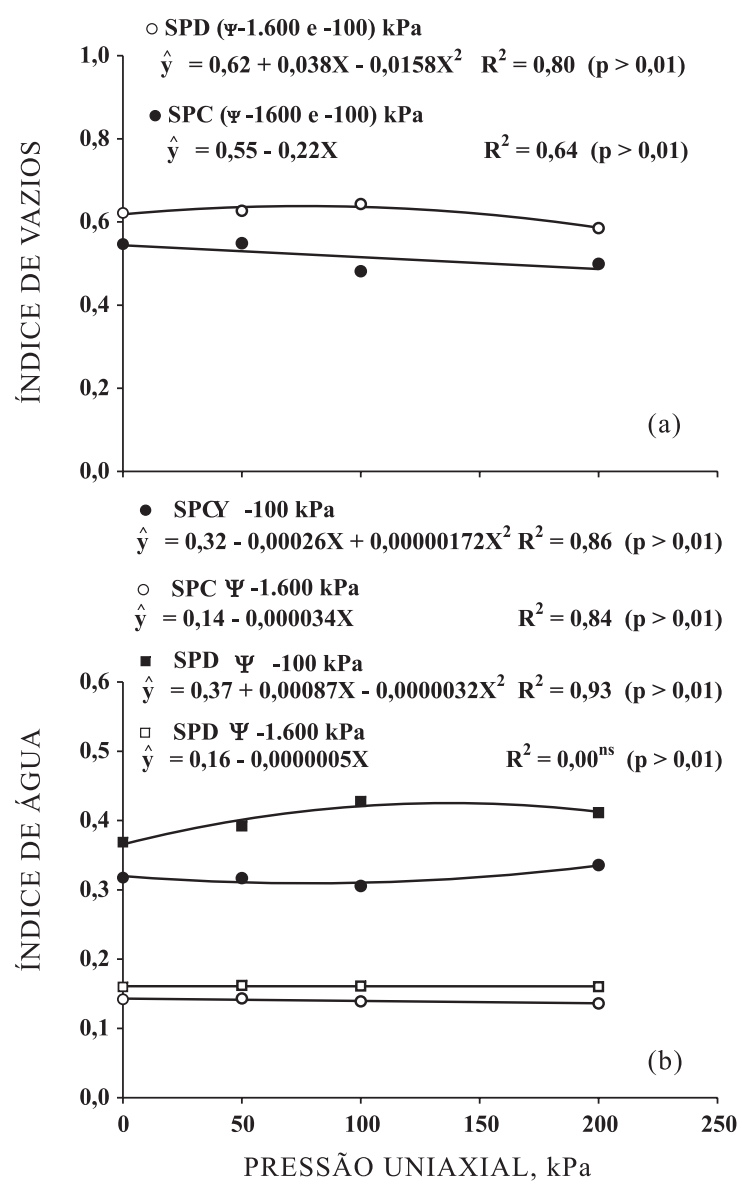

Figura 4. Relação entre índices de vazios (a) e água (b) de um Argissolo Vermelho-Amarelo distrófico abrúptico, profundidade de 0-0,075 m, sob dois sistemas de preparo do solo (SPC e SPD) em funções de níveis crescentes de compressão unidimensional aplicados (zero, 50, 100 e 200) $\mathrm{kPa}$.

em cada potencial de água e vice-versa. Assim, em ambos os sistemas, observa-se menor índice de ar para o potencial de água no solo de $-1.600 \mathrm{kPa}$ (Figura 5). Relacionando-se o sistema de manejo, percebe-se (Figura 5b), que o SPC apresenta menor índice de ar em todas as condições de pressão aplicadas ao solo. Esses resultados confirmam os de Horn \& Rostek (2000), que verificaram diminuição na porosidade de aeração com o aumento da pressão aplicada, sendo esta em maior intensidade no sistema com revolvimento do solo. Essa propriedade é importante porque interfere na disponibilidade de ar para as raízes das plantas e nos processos de respiração e de troca de nutrientes regidos pelo processo de oxirredução (Stepniewski et al., 2002).

Os resultados demonstram que a aplicação de níveis crescentes de estresse mecânico nos ensaios de compressão unidimensional, mesmo sob pressões consideradas fracas (zero e 50) $\mathrm{kPa}$, produz efeitos negativos sobre a estrutura do solo e a repartição do espaço poroso entre o ar e a água. Tais pressões situam- se freqüentemente abaixo das pressões historicamente submetidas ao solo, logo mantêm as características do espaço poroso do solo (Dias Junior, 2000). No entanto, as alterações na densidade e no conteúdo de água do solo em função da pressão aplicada, embora do ponto de vista agronômico tenham sido pressões pequenas, foram significativas. Isto contempla a hipótese do trabalho de que pressões, mesmo pequenas, podem alterar a organização da fase sólida e a proporção das fases líquida e gasosa do solo.

O conteúdo de água do solo tendeu ao incremento com a diminuição do espaço poroso ocupado por ar $(r=-0,85)$. Em contrapartida, a proporção de ar que ocupa o espaço poroso diminuiu intensamente, em ambos os sistemas, com as pressões aplicadas, porém com mais intensidade para o solo sob SPC. Isso indica que pequenas variações ocorridas no espaço poroso do solo em função do rearranjo da estrutura da matriz sólida aos estresses sofridos podem alterar profundamente a proporção entre a água e o ar nesse espaço. A princípio, o índice de ar (Figura 5), parece

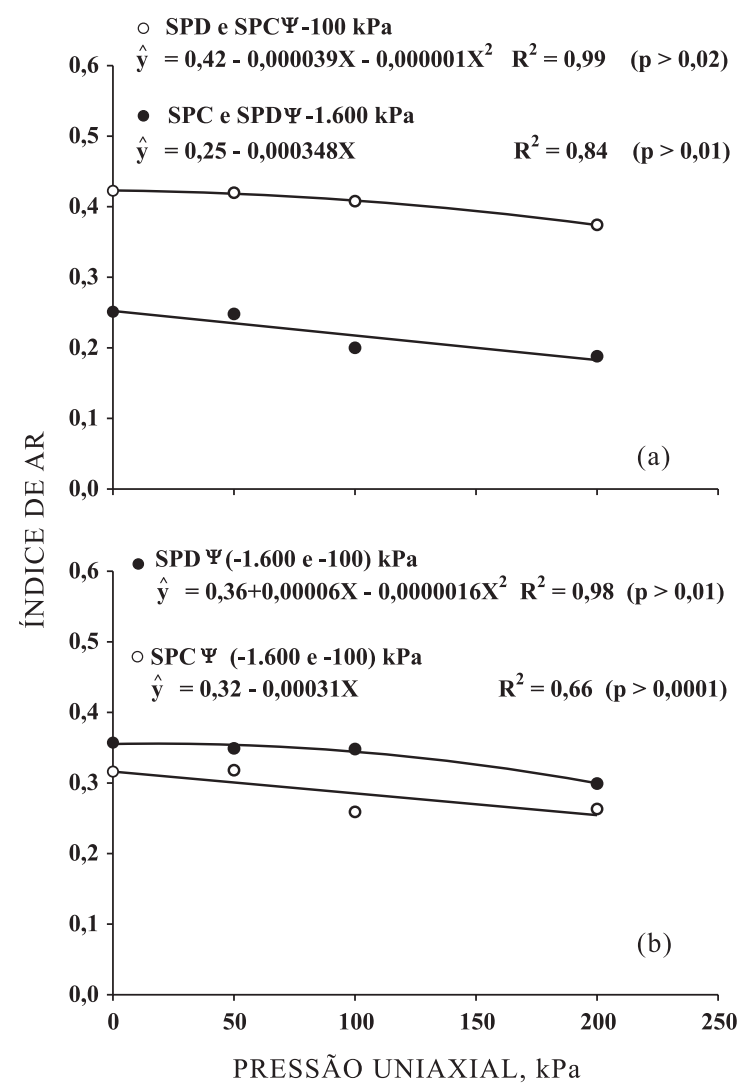

Figura 5. Relação entre índices de ar em ambos os sistemas de preparo do solo (a) e dentro de um sistema e com ambos os potenciais de água no solo (b) de um Argissolo Vermelho-Amarelo distrófico abrúptico, profundidade de 0-0,075 m, sob dois sistemas de preparo do solo (SPC e SPD) em funções de níveis crescentes de compressão unidimensional aplicados (zero, 50, 100 e 200) $\mathrm{kPa}$. 
ser mais alterado que o índice de água, e isso pela reorganização do espaço poroso em resposta ao aumento do estresse aplicado ao solo.

É provável que haja uma reorganização, dentro da microporosidade, das partículas finas como as argilas, o silte e a matéria orgânica, diminuindo o espaço antes ocupado pelo ar. Contudo, a própria porosidade pode ter sido alterada, diminuindo a proporção de ar em ambos os potenciais de água no solo $(-100$ e $-1600 \mathrm{kPa})$, porque o aumento no conteúdo de água, potencial de água de $-100 \mathrm{kPa}$, somente pode ser relacionado a uma maior porosidade.

É importante notar que o solo sob SPC tendeu a ser mais sensível quanto ao seu espaço poroso com o estresse aplicado. Contudo, os efeitos dos níveis crescentes de compressão unidimensional aplicados, considerando a retenção de água ao potencial de -100 kPa, foi de maior magnitude para o solo sob SPD. De certa forma, o aumento desse conteúdo de água é benéfico e desejado, visto que pode contribuir para o aumento do limite superior de água, resultando em maior disponibilidade de água para as plantas. Entretanto, isso vem acompanhado do aumento na densidade do solo, que pode refletir em maior resistência à penetração das raízes, característica muito importante para solos arenosos (Secco et al., 2004; Collares et al., 2006). A reestruturação do espaço poroso como resposta ao estresse aplicado pode ser visualizada pelo aumento de diâmetros de poros responsáveis pela maior retenção de água ao potencial de $-100 \mathrm{kPa}$. Vale ressaltar que esse potencial representa o conteúdo de água no solo próximo à capacidade de campo ou, como denominado por Carlesso (1995), limite superior de conteúdo de água. Assim, em geral, tem-se uma resposta similar do conteúdo de água entre os níveis de compressão unidimensional para o potencial de $-1.600 \mathrm{kPa}$, benéfica até certo ponto (100 kPa de pressão) para o SPD, mas apresenta efeitos deletérios na qualidade do espaço ocupado por ar e água do solo.

\section{CONCLUSÕES}

1. O solo sob preparo convencional é mais sensível à compressão unidimensional aplicada que sob plantio direto, indicado pela maior magnitude na diminuição do espaço poroso e da proporção de ar do solo.

2. Níveis de compressão unidimensional crescentes incrementam a densidade do solo e o conteúdo de água para o potencial de $-100 \mathrm{kPa}$ em ambos os sistemas de preparo.

3. O conteúdo de água no solo no potencial de -1.600 kPa não foi sensível aos fatores de variação ocasionados pelo sistema de preparo, nem pelas pressões aplicadas nos ensaios de compressão unidimensionais.

\section{AGRADECIMENTOS}

Os autores agradecem à Unidade PESSAC do Centro INRA de Versailles (França) e ao Laboratório G3S da École Polytechnique de Palaiseau (França) pela infra-estrutura das análises. O primeiro autor agradece o CNPq pela concessão de bolsa de doutorado pleno no exterior.

\section{LITERATURA CITADA}

ABREU, S.L.; REICHERT, J.M. \& REINERT, D.J. Escarificação mecânica e biológica para a redução da compactação em Argissolo franco-arenoso sob plantio direto. R. Bras. Ci. Solo, 28:519-531, 2004.

ALBUQUERQUE, J.A.; SANGOI, L. \& ENDER, M. Efeitos da integração lavoura-pecuária nas propriedades físicas do solo e características da cultura do milho. R. Bras. Ci. Solo, 25:717-723, 2001.

ALCÂNTARA, E.N. \& FERREIRA, M.M. Efeitos de métodos de controle de plantas daninhas na cultura do cafeeiro (Coffea arábica L.) sobre a qualidade física do solo. R. Bras. Ci. Solo, 24:711-721, 2000.

ANDREOLI, M. \& TELLARINI, V. Farm sustainability evaluation: Methodology and practice. Agric., Ecosyst. Environ., 77:43-52, 2000.

BASTET, G.; BRUAND, A.; QUÉNTIN, P. \& COUSIN, I. Estimations des propriétés de rétention en eau des sols à l'aide de fonctions de pédotransfert (FPT): Une analyse bibliographique. Étude Gestions Sols, 5:7-23, 1998.

BEUTLER, A.N.; CENTURION, J.F.; ROQUE, C.G. \& FERRAZ, M.V. Densidade relativa ótima de Latossolos Vermelhos para a produtividade de soja. R. Bras. Ci. Solo, 29:843-849, 2005.

BOIZARD, H.; RICHARD, G.; ROGER-ESTRADE, J.; DÜRR, C. \& BOIFFIN, J. Cumulative effects of cropping systems on the structure of the tilled layer in Northern France. Soil Till. Res., 34:149-164, 2002.

BORTOLUZZI, E.C.; RHEINHEIMER, D.S.; KAMINSKI, J.; GATIBONI, L.C. \& TESSIER, D. Alterações na mineralogia de um Argissolo do Rio Grande do Sul submetido a fertilização potássica. R. Bras. Ci. Solo, 29:327$335,2005 a$.

BORTOLUZZI, E.C.; RHEINHEIMER, D.S. \& TESSIER, D. An estimation of water retention properties in sandy soils of Southern Brazil In: SYMPOSIUM INTERNATIONAL ON THE MANAGEMENT OF TROPICAL SANDY SOILS FOR SUSTAINABLE AGRICULTURE: A holistic approach for sustainable development of problem soils in the tropics, 1., Khon Kaen, 2005. Proceedings. Khon Kaen, FAO, 2005b. p.189-193.

BORTOLUZZI, E.C.; VELDE, B.; PERNES, M.; DUR, J-C. \& TESSIER, D. Vermiculite with hydroxy-aluminuim interlayer and kaolinite formation in a subtropical soil from South Brazil. Clay Miner., 43:155-163, 2008. 
BRAIDA, J.A.; REICHERT, J.M.; VEIGA, M. \& REINERT, D.J. Resíduos vegetais na superfície e carbono orgânico do solo e suas relações com a densidade máxima obtida no ensaio de Proctor. R. Bras. Ci. Solo, 30:605-614, 2006.

BRUAND, A. Contribution à l'étude de la dynamique de l'organisation de matériaux gonflants. Application à un matériau argileux d'un sol argilo-limoneux de l'Auxerrois. Paris, University Paris VII, 1985. 225p.(Thèse Dr. Spécialité)

BRUAND, A.; HARTMANN, C. \& LESTURGEZ, G. Physical properties of tropical sandy soils: A large range of behaviours. In: SYMPOSIUM INTERNATIONAL ON THE MANAGEMENT OF TROPICAL SANDY SOILS FOR SUSTAINABLE AGRICULTURE: A holistic approach for sustainable development of problem soils in the tropics, 1., Khon Kaen, 2005. Proceedings. Khon Kaen, FAO, 2005 p.148-158.

BRUAND, A. \& TESSIER, D. Water retention properties of the clay in soils developed on clayey sediments: Significance of parent material and soil history. Eur. J. Soil Sci., 51:679-688, 2000.

CANALI, L.B. \& ROLOFF, G. Influência do preparo e da correção do solo na condição hídrica de um Latossolo Vermelho-Escuro sob plantio direto. R. Bras. Ci. Solo, 21:99-104, 1997.

CARLESso, R. Absorção de água pelas plantas: Água disponível versus extraível e a produtividade das culturas. Ci. Rural, 25:183-188, 1995.

CARTER, M.R.; ANGERS, D.A. \& TOPP, G.C. Characterizing equilibrium physical condition near the surface of a fine sandy loam under conservation tillage in a humid climate. Soil Sci., 164:101-110, 1999.

COLLARES, G.L.; REINERT, D.J.; REICHERT, J.M. \& KAISER, D.R Qualidade física do solo na produtividade da cultura do feijoeiro num Argissolo. Pesq. Agropec. Bras., 41:1663-1674, 2006

CORRECHEL, V.; SILVA, A.P. \& TORMENA, C.A. Influência da posição relativa à linha de cultivo sobre a densidade do solo em dois sistemas de manejo do solo. R. Bras. Ci. Solo, 23:165-173, 1999.

DELAGE, P. \& FRY, J.J. Comportement des sols compactés: Apports de la mécanique des sols non saturés. Rev. Française Géotechn., 22:17-29, 2000.

DELAGE, P. \& CUI, Y.J. Comportement mécanique des sols non saturés. Techniques d'ingénieur. C302, Traité Construction, 2001. 20p.

DIAS JUNIOR, M.S. Compactação do solo. In: NOVAIS, R.F.; ALVAREZ V., V.H. \& SCHAEFER, C.E., eds. Tópicos em ciência do solo. Viçosa, MG, Sociedade Brasileira de Ciência do Solo, 2000. v.1. p.55-94.

DURAN, J.; KOLB, E. \& VANEL, L. Static friction and arch formation in granular materials. Am. Physical Soc., 58:805-810, 1998.

EMPRESA BRASILEIRA DE PESQUISA AGROPECUÁRIA EMBRAPA. Sistema brasileiro de classificação de solos. 2.ed. Brasília, 2006. 306p.
GENRO JUNIOR, S.A.; REINERT, D.J. \& REICHERT, J.M. Variabilidade temporal da resistência à penetração de um Latossolo argiloso sob semeadura direta com rotação de culturas. R. Bras. Ci. Solo, 28:477-484, 2004.

HÅKANSSON, I.; VOORHEES, W.B. \& RILEY, H. Vehicle and wheel factors influencing soil compaction and crop responses in different traffic regimes. Soil Till. Res., 11:239-282, 1988.

HILL, R.L. Long-term conventional and no-tillage effects on selected soil physical properties. Soil Sci. Soc. Am. J., 54:161-166, 1990.

HORN, R. \& LEBERT, M. Soil compactability and compressibility. In: SOANE, B.D. \& van OUWERKERK, C., eds. Soil compaction in crop production. Amsterdam, Elsevier, 1994. p 45-69.

HORN, R. \& ROSTEK, J. Subsoil compaction process-state of knowledge. In: HORN, R.; van den AKKER, J.J.H. \& ARVIDSSON, J. Subsoil compaction: Distribution, processes and consequences. Adv. Geoecol., 32:44-54, 2000 .

LARSON, W.E.; GUPTA, S.C. \& USECHE, R.A. Compression of agricultural soils from eight soil orders. Soil Sci. Soc. Am. J., 44:450-457, 1980.

LESTURGEZ, G.; HARTMANN, C.; TESSIER, D. \& POSS, R. Compaction process in a tilled sandy soil. Physical properties of tropical sandy soils. In: SYMPOSIUM INTERNATIONAL ON THE MANAGEMENT OF TROPICAL SANDY SOILS FOR SUSTAINABLE AGRICULTURE: A holistic approach for sustainable development of problem soils in the tropics, 1., Khon Kaen, 2005. Proceedings. Khon Kaen, FAO, 2005. p.159-167.

KONDO, M.K. \& DIAS JUNIOR, M.S. Compressibilidade de três Latossolos em função da umidade e uso. R. Bras. Ci. Solo, 23:211-218, 1999.

MEROTTO JÚNIOR, A.; \& MUNDSTOCK, C.M. Wheat root growth as affected by soil strength. R. Bras. Ci. Solo, 23:197-202, 1999 .

MONNIER, G.; STENGEL, P. \& FIES, J.C. Une méthode de mesure de la densité apparente de petits agglomérats terreux: application à l'analyse des systèmes de porosité du sol. Ann. Agron., 24:533-545, 1973.

PANAYIOTOPOULOS, K.P. \& MULLINS, C.E. Packing of sands. J. Soil Sci., 36:129-139, 1985.

PERNES-DEBUYSER A. \& TESSIER, D. Soil physic properties affected by long term fertilizer. Eur. J. Soil Sci., 55:505512,2004

PROST, R.; KOUTIT, T.; BENCHARA, A. \& HUARD, E. State and location of water adsorbed on clay minerals: Consequences of the hydration and swelling-shrinkage phenomena. Clays Clay Miner., 46:117-131, 1998.

REINERT, D.J.; REICHERT, J.M. \& SILVA, V.R. Propriedades físicas de solos em sistema plantio direto irrigado. In: CARLESSO, R.; PETRY, M.T.; ROSA, G.M. \& CERETTA, C.A., eds. Irrigação por aspersão no Rio Grande do Sul. Santa Maria, 2001. 165p. 
RICHARDS, B.G.; BAUMGARTL, T. \& HORN, R. Modelling coupled processes in structured unsaturated soils Theory and examples. Adv. Geoecol., 32:175-190, 2000.

RICHARDS, L.A. A pressure - membrane extraction apparatus for soil solution. Soil Sci., 51:377-386, 1941.

SECCO, D.; REINERT, D.J.; REICHERT, J.M. \& DA ROS, C.O. Produtividade de soja e propriedades físicas de um Latossolo submetido a sistemas de manejo e compactação. R. Bras. Ci. Solo, 28:797-804, 2004.

SILVA, V.R.; REINERT, D.J. \& REICHERT, J.M. Fatores controladores da compressibilidade dos solos Argissolo Vermelho-Amarelo distrófico arênico e Latossolo Vermelho distrófico típico. I. Estado Inicial de compactação. R. Bras. Ci. Solo, 26:1-8, 2002a.

SILVA, V.R.; REINERT, D.J. \& REICHERT, J.M. Fatores controladores da compressibilidade dos solos Argissolo Vermelho-Amarelo distrófico arênico e Latossolo Vermelho distrófico típico. II. Grau de saturação de água. R. Bras. Ci. Solo, 26:9-16, 2002b.

SILVA, V.R.; HORN, R.; REICHERT, J.M.; REINERT, D.J. \& BRAIDA, J.A. Variações no potencial matricial e na deformação do solo durante o ensaio de compressibilidade e de cisalhamento direto. In: REUNIÃO BRASILEIRA DE MANEJO E CONSERVAÇÃO DO SOLO E DA ÁGUA, 15., Santa Maria, 2004. Anais. Santa Maria, 2004. 4p. CD ROM.
STEPNIEWSKI, W.; HORN, R. \& MARTYNIUK, S. Managing soil biophysical properties for environmental protection. Agric. Ecossyst. Environ., 88:175-181, 2002.

STONE, L.R. \& SILVEIRA, P.M. Effects of tillage systems and crop rotation on soil porosity and bulk density. R. Bras. Ci. Solo, 25:395-401, 2001.

STONE, R.J. \& EKWUE, E.I. Maximum bulk density achieved during soil compaction as affected by the incorporation of three organic materials. Trans. Am. Soc. Agric. Eng., 36:1713-1719, 1993.

TAVARES FILHO, J.; BARBOSA, G.M.C.; GUIMARÃES, M.F. \& FONSECA, I.C.B. Resistência do solo à penetração e desenvolvimento do sistema radicular do milho (Zea mays) sob diferentes sistemas de manejo em um Latossolo Roxo. R. Bras. Ci. Solo, 25:725-730, 2001.

TEDESCO, M.J.; GIANELLO, C.; BISSANI, C.A.; BOHNEN, H. \& VOLKWEISS, S.J. Análise de solo, plantas e outros materiais. 2.ed. Porto Alegre, Universidade Federal do Rio Grande do Sul, 1995. 174p. (Boletim Técnico de Solos)

TRAUTNER, A.; van den AKKER, J.J.H.; FLEIGE, H.; ARVIDSSON, J. \& HORN, R. A subsoil compaction database: Its development, structure and content. Soil Till. Res., 73:9-13, 2003.

UNGER, P.W. \& JONES, O.R. Long-term tillage and cropping systems affect bulk density and penetration resistance of soil cropped to dryland wheat and grain sorghum. Soil Till. Res., 45:39-57, 1998.

WASHBURN, E.W. The dynamics of capillary flow. Phys. Rev., 17:273, 1921. 